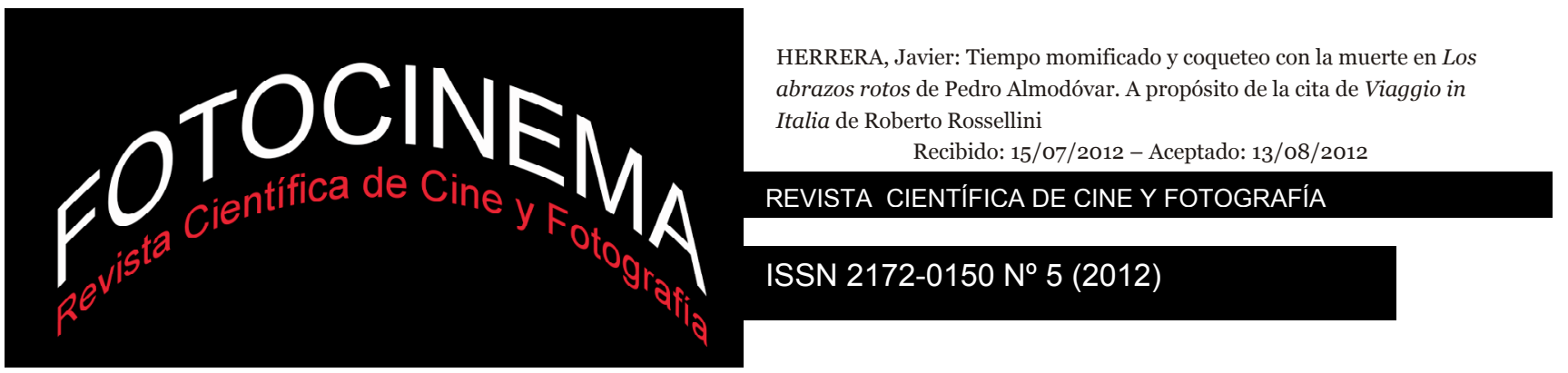

\title{
TIEMPO MOMIFICADO Y COQUETEO CON LA MUERTE EN LOS ABRAZOS ROTOS DE PEDRO ALMODÓVAR. A PROPÓSITO DE LA CITA DE VIAGGIO IN ITALIA DE ROBERTO ROSSELLINI \\ MUMMIFIED TIME AND FLIRTING WITH DEATH IN PEDRO ALMODÓVAR'S BROKEN EMBRACES. ABOUT THE QUOTATION OF ROBERTO ROSSELLINI'S VIAGGIO IN ITALIA
}

\section{Resumen:}

Desde nuestro punto de vista Los Abrazos rotos supone dentro de la trayectoria de Almodóvar una culminación provisional de todas las características que han definido la peculiaridad de su estilo posmoderno, una de las cuales, el robo de imágenes procedentes de otras películas y otros directores, se ha convertido casi en una obsesión. Dentro de ese proceder, en dicha película, adquiere especial relevancia una cita directa que realiza de una secuencia muy reveladora de Viaggio in Italia de Roberto Rossellini que le sirve a Almodóvar para plantear la relación amor-muerte de una forma muy original y así apropiarse para sí del concepto rosselliniano del cine como fluir de la vida y alejarse de la concepción del cine como versión de la realidad.

\section{Palabras clave:}

Los abrazos rotos; Roberto Rossellini; Viaggio in Italia; amor y muerte; imágenes robadas; cita fílmica.

\section{Key words:}

Broken Embraces; Roberto Rossellini; Viaggio in Italia; love and death; stolen images; film quotation.

\section{Javier Herrera \\ Filmoteca Española}

\begin{abstract}
:
Broken Embraces can be considered a provisional culmination of all the characteristics that defined the peculiarity of Almodovar's postmodern style. One of these characteristics, which has become almost an obsession, is the theft of images from other films and directors. In this regard, a direct quotation he makes of Roberto Rossellini's Viaggio in Italia acquires special relevance. Almodóvar uses this reference in order to pose the love-death connection in a very original fashion while appropriating rosselinian concept of film as course of life and moving away from the idea of film as a version of reality.
\end{abstract}




\section{La mirada del travestí y el robo de imágenes como fundamento del estilo almodovariano}

Es en Todo sobre mi madre cuando Almodóvar consigue por fin un estilo personal y distinguible, plena y sólidamente posmoderno, en base no a la suma del sinnúmero de operaciones intertextuales de todo tipo que pueden detectarse en esa obra (Poyato, 2007) sino a través de las imitación de estilos y géneros que lleva a cabo (lo que hemos denominando "territorio del pastiche"1) y, sobre todo, de la transformación de infinidad de imágenes "robadas" a otros directores, fruto de su experiencia como espectador "cinéfilo" por excelencia en la oscuridad de las salas de cine. Es lo que hemos llamado la "mirada travestida" que no es sino una consecuencia lógica de su identificación con el tipo sociopsico-sexual del travestí, manifestada tanto en la profusión de esos personajes en su obra como en operaciones retóricas, llamadas travestimientos, que se incluyen en la trama sin ningún tipo de miramientos. A través de esas presencias -en Todo..., se acentúa aún más que en las veces anteriores la importancia concedida al travestí como elemento perturbador a través de la figura de un padre llamado Lola- Almodóvar pretende introducir en la dualidad normativa masculino/femenino, y en los consiguientes patrones de mirada a ella asociados, un tercer elemento indefinible, amenazante y anormal, que puede ser asimilable a lo monstruoso porque produce "un colapso de la norma fálica" e interfiere "la operación de sutura del cine dominante" (Yarza, 1999: 206).

Además, es también en esta película donde la tendencia al "robo" se manifiesta igualmente de un modo más rotundo, literal y explícito: de un lado, el pase televisivo de All about Eve (Eva al desnudo, 1951) de Joseph L. Mankiewicz y de otro la escena del accidente de Opening Night (Noche de extreno, 1978) de John Cassavetes. Si en el primer caso asistimos a un claro ejemplo de "cita literal", muy similar a la empleada en Carne trémula (1997) con Ensayo de un crimen (1955) de Buñuel, que nos sitúa en un contexto teatral y en un problema de

\footnotetext{
${ }^{1}$ Hemos desarrollado este concepto así como los de "imágenes robadas" y la "mirada travestida", que nos parecen claves para entender el estilo almodovariano, en tres ensayos para otras tantas ediciones recopilatorias de textos acerca de Almodóvar. El único publicado hasta la fecha (Mellen Press) es el que aparece reseñado en la bibliografía (Herrera 2012). Los otros dos, uno editado por Marvin d’Lugo y Kathleen Vernon y el otro por Jorge González del Pozo, aparecerán publicados por Blackwell y la Michigan State University respectivamente.
} 
vampirización entre grandes actrices, el segundo es un claro ejemplo de ese mirar travestido típicamente suyo, en el que conviene detenerse un poco para mostrar dicho proceder. En la obra de Cassavetes, Nancy, una joven de 17 años, espera la salida de su actriz favorita, Gena Rowlands, para pedirle un autógrafo; tras abrirse paso entre la multitud que hay a las puertas del teatro, logra llegar hasta la estrella, que se encuentra dentro del coche. Llueve torrencialmente. Nancy pegada a la ventanilla no para de lanzarle besos y decirle que la quiere pero cuando el coche de la actriz se pone en marcha, otro coche la atropella. En la película de Almodóvar, Esteban (Eloy Azorín), que tiene la misma edad que Nancy, hijo de Manuela (Cecilia Roth), tras esperar los dos bajo la lluvia la salida del teatro de su actriz favorita, Huma Rojo (Marisa Paredes), para que le firme un autógrafo, es atropellado por un coche; sin embargo (y he aquí el rasgo distintivo de Almodóvar), a pesar de las concordancias de la anécdota (admiración de dos jóvenes por una actriz y la petición del autógrafo a la salida del teatro), de la edad, la lluvia, la noche y el atropello, el manchego introduce dos variantes para camuflar el origen y hacer suyo el resultado. El mismo lo explica de la siguiente manera:

"En Opening Night la escena está rodada a la altura de los ojos... El fan que pide el autógrafo de Gena Rowlands se arrodilla ante ella y ella es muy directa, va hacia el coche y le habla... Pero en mi film, se trata de una madre y de su hijo que esperan la salida de los artistas y que, en esta especie de vacío de la espera, intercambian las palabras más importantes de su vida... La escena, pues, tiene otra significación... Pero en el film de Cassavetes la actriz que representa Gena Rowlands comprende lo que ha pasado, quiere saber lo que le ha sucedido a su admiradora. Yo preferí que el personaje de Marisa [se refiere al personaje Huma Rojo que interpreta Marisa Paredes] desapareciera sin saber lo que había ocurrido. Y para el accidente, puse la cámara en el lugar de los ojos de Esteban" (Strauss, 1999: 39. Traducción nuestra).

He aquí un caso típico de lo que Almodóvar llama "robo" pero que se trata realmente de un travestimiento ${ }^{2}$ en toda regla porque, a pesar de que Almodóvar cambia el punto de vista de la cámara -lo que Poyato llama "la mirada del muriente" (2007: 92-95)-, añade un personaje más a la espera de la actriz famosa y esta no sabe nada del atropello; se trata de elementos circunstanciales que, por supuesto, Almodóvar aprovechará para sus fines pero que no trastocan el sentido de la secuencia original que no es otro que mostrar

\footnotetext{
2 Recordemos que para Genette el travestimiento "se hace siempre sobre un (o varios) texto (s)
} singular (es), nunca sobre un género” (1989: 103). 
cómo el azar puede en un instante truncar la vida de una persona haciéndole transitar, acaso en uno de los días más felices de su vida -acercarse a la actriz idolatrada-, desde el máximo de felicidad al fatalismo de la muerte; una idea, por otro lado, sumamente poética: la imposibilidad del disfrute pleno de la sublimidad del arte, que en su caso es recurrente pues la volveremos a encontrar en Los abrazos rotos.

Así pues, tendríamos que "lo almodovariano", en lo que respecta al uso que hace del cine de otros directores, consistiría en crear una película diferente a partir de las películas de otros pero que mantendría con ellas un "diabólico" (para utilizar la terminología en su día usada por Umbral) (D’Lugo, 2005: 84) hilo conductor que las conectaría y al mismo tiempo las subvertiría, las desnaturalizaría e incluso las mezclaría entre sí; se trataría entonces de un estilo fundado en el pastiche como procedimiento imitativo y en el travestimiento como procedimiento de transformación: de igual modo que el travestí puede convertirse en muchos "otros" en cuanto a aspecto, es decir copiar, imitar su "imagen", sin embargo no puede por mucho que quiera "ser" ese otro, teniendo que aceptar su personalidad dual y equívoca, que es lo que provoca una distorsión en el sistema binario masculino/femenino. Desde ese punto de vista, pues, "lo almodovariano" coincide con las tesis de Genette (146) cuando afirma -y es lo más característico, personal y original en Almodóvar- que en el travestimiento puede haber parte de pastiche pero nunca al contrario; $\mathrm{y}$ efectivamente en sus acusados procesos de transformación de imágenes de otros directores caben pastiches de todas clases en cuanto que se imitan los clichés, los estereotipos o las convenciones de género, estéticas o de lenguaje de películas concretas pero -y he ahí la singularidad- cuando se decide a imitar un estilo autorial (Warhol por ejemplo), un movimiento (como el neorrealismo) o una tendencia de moda (las películas de Lester), tal y como sucede en sus primeras películas, los travestimientos se reducen al máximo aunque aumenta el tono y las transformaciones operadas por la parodia. Dicho proceso, que es sintomático de la búsqueda de un estilo propio, es el que culmina en Todo sobre mi madre y no hace sino acentuarse, una vez logrado, en cada película posterior con un mayor grado de complejidad argumental, alarde de virtuosismo y referencias culturales. 
Asi, por ejemplo, en su siguiente película, Hable con ella, logrará fundirlos con especial maestría al integrar una pequeña película muda, El amante menguante, que remite a la clásica de Jack Arnold, The Incredible Shrinking Man (El increíble hombre menguante, 1957) pero que al mismo tiempo, según sus propias palabras, está inspirada en Sunrise (1927) de Murnau3; es decir por un lado hay una clara imitación de estilo (la estética y formato del cine mudo, la poética concreta de Murnau) y por otro ha transformado de forma lúdicosatírica (es decir parodia + travestimiento) el film de Arnold, que al ser integrado dentro de otra obra que a su vez contiene abundantes travestimientos de Persona (Persona, 1966) de Ingmar Bergman 4 , ha acentuado su valor prototípico como mirada travestida por antonomasia al introducirnos virtualmente en un "espacio de lo abyecto" (Yarza, 1999: 206) que el travestí convoca, un espacio que en esa película se resuelve de una manera ciertamente monstruosa: con la violación por parte del enfermero Benigno -no explicitada porque la película muda sirve de "tapadera" de la realidad vivida a diario en la habitación del hospital (Maurer, 2009: 142)- de una mujer en coma, Alicia, de la que está enamorado y a la que, al dejarle embarazada, le devuelve, paradójicamente, a la vida.

Con La mala educación se produce una vuelta de tuerca más en la complejidad narrativa del pastiche almodovariano al integrar, según el modelo clásico de la "construcción en abismo" metacinematográfica, dentro de la película el rodaje de otra película, titulada La visita. A pesar de que Almodóvar no resuelve bien la fusión entre las dos ficciones (habría que hablar más de confusión), sin embargo se produce un avance muy notable en lo que respecta a su mirada travestida y lo que tiene de irrupción del monstruo en el momento en que la película discurre por las convenciones del cine negro y los personajes perpetran acabar con Ignacio, y, tras asistir a una sesión de ese tipo de cine dentro de un festival especializado, les invade el sentimiento de culpa y ya, sin máscaras ni chantajes y condicionamientos, se entregan con desenfreno a su pasión amorosa

\footnotetext{
3 "De todos los films mudos que yo he visto antes de abordar El amante menguante, ha sido Amanecer el que se correspondía mejor con mis intenciones. Incluso la letra de los cartones, como si fuera una escritura manuscrita, me ha inspirado" (Almodóvar, 2006).

4 Esta relación ha sido sobre todo destacada por estudiosos franceses de su obra, concretamente Bremard, 2003, J-L.L, 2006 y Law, 2010.
} 
y voyeurística 5 ; en efecto, el travestimiento está aquí señalado tanto por la inversión de los convencionalismos respecto a la pareja convencional de amantes (se trata de homosexuales) como por la condición de travestí del personaje de Ignacio y de las actuaciones de su hermano Angel interpretándolo, presencias que, cada vez que aparecen, alteran en un sentido transgresor la normalidad del relato, llevándolo al terreno más almodovariano por excelencia.

Desde el punto de vista de la mirada travestida, Volver -como el propio título indica- supone un aparente retroceso porque no hay travestimientos explícitos y el monstruo ha sido sustituído por un fantasma; por otro lado, aunque se produce un retorno a las fuentes primigenias de la poética neorrealista, su tendencia al pastiche, esta vez de películas de fantasmas, está más contenida e incluso la cita explícita de Bellissima (Bellísima, 1951) de Luchino Visconti, sirve para reforzar la condición maternal por excelencia del personaje de Penélope Cruz relacionándola con la gran Anna Magnani. Por otro lado, se percibe de una forma cada vez más patente el deseo de organizar el relato de una forma cada vez más equívoca entre, por una parte, la tradición productora de imágenes, puramente cinefílica, y la realidad, una realidad cada vez más artificialmente creada a imagen y semejanza de esos modelos ficticios y más alejados de la realidad objetiva. Desde esa óptica, al menos, tenemos una novedad importante para el discurso que nos ocupa pues supone el primer enfrentamiento de la mirada travestida con uno de los dos polos vitales de esa realidad hasta ahora enmascarada: nos referimos a la muerte. En efecto, es la primera película en la que se explicita el miedo personal que tiene Almodóvar a la muerte mediante "una cierta reflexión sobre su inevitabilidad y la necesidad de su aceptación" (Alarcón, 2006: 58); pero casi diríamos más: se trataría de la constatación racional de la imposibilidad de la vida después de la muerte, salvo que la imagen -“el cine nos sobrevive”, llega a decir en una ocasión (Sardá, 2009: 47)pudiera ejercer ilusoriamente esa función y resucitarnos.

\footnotetext{
5 Recordemos que Berenguer graba con su cámara de vídeo el rostro de Angel mientras están follando en un intento por perpetuar lo más posible esos instantes de máximo placer; esa actitud "prolongadora" del medio reproductor lo tendremos también en Los abrazos rotos cuando Mateo capta con su cámara reflex el instante de máxima felicidad con Lena acoplados en el sofá tras haber visto en televisión el pase de Te querré siempre.
} 


\section{Y en el principio fue la fotografía}

Consolidada plenamente la mirada travestida con el mínimo arsenal de procesos transformadores pero con el máximo de autorreferencias -de citas, de parodias, de recurrencias- y aceptando la posibilidad de la extinción implícita en el monstruo, con Los abrazos rotos realiza una suerte de intento de síntesis de todos los contrarios anteriormente citados comenzando por una de sus más socorridas obsesiones artísticas: fusionar el melodrama con el noir, que es al mismo tiempo una de las características fundamentales de la mirada del travestí. De otro lado, también es perceptible otra característica de esa mirada como es el actuar al mismo tiempo como espectador y como director y representarse en esa dualidad a través de personajes interpuestos que hacen sus veces: ya sea los que ven películas en el cine o en pases televisivos o bien sus alter ego ${ }^{6}$, el último de los cuales, Mateo Blanco/Harry Caine (Lluis Homar), es un continuador de la estela de Pablo Quintero (Eusebio Poncela) en La ley del deseo (1986), de Máximo Espejo (Francisco Rabal) en Atame (1989) y de Enrique Goded (Fele Martínez) en La mala educación (2004), y aúna al mismo tiempo, además de ese natural interés cinefílico, las otras dos facetas más importantes de la creación cinematográfica: la de director y la de guionista; no obstante, Almodóvar precisa que en todos ellos "hay un reflejo mío, pero en ninguno hay demasiados datos biográficos” (Heredero-Reviriego, 2009: 8).

Un matiz que se añade a lo ya dicho es la precisión de que todas las referencias que lleva a cabo del cine de otros las hace en tanto que espectador y no como realizador, lo cual nos demuestra hasta qué punto los espectadores que aparecen en sus películas viendo películas no son sino interposiciones o proyecciones de sí mismo en la pantalla: “el cine -afirma- es una experiencia muy personal y yo siempre he querido recordar lo que yo sentía cuando descubrí esos films" (Ciment-Rouyer, 2009: 11). No es extraño, en consecuencia, que Los abrazos rotos haya sido considerada por más de un observador autorizado (Grenier, 2010; Kinder, 2010) como un equivalente respecto a la carrera de Almodóvar de lo que significó 8 1/2 (8 y medio, 1963) respecto a la de Fellini (Metz, 1972: 7) pues no se trata sólo de que haya una referencia a la mítica película ni de la admiración siempre reconocida que profesa al director italiano,

\footnotetext{
${ }^{6}$ Sobre el tema de las duplicidades, dualidades, desdoblamientos, etc. remito a Herrera 2012.
} 
sino de que en ella también hay una reflexión sobre su oficio a través de una mirada retrospectiva hacia todo lo que de cine hay dentro de su obra anterior. Se trata, pues, de una obra síntesis que refleja más que ninguna otra su pasión cinéfila y su mundo personal como hilvanador de imágenes, unas imágenes que son tan reales para él como la misma realidad, "como si las imágenes de las ficciones sólo pudieran llenarse de ficciones para decir las realidades" (Seguin, 2009: 180). Pero, aparte esa función de síntesis, Los abrazos rotos tiene un aspecto, nada original por cierto, pero que le dota, por su carácter autobiográfico, de una apreciable singularidad: la importancia que se le concede a la fotografía no sólo como imagen generadora de la ficción sino como prolongación de la vida en el recuerdo, como conformadora de la memoria, como momificación del tiempo. En relación con la génesis de la película, el propio director ha repetido que la primera idea, la primera línea de su historia, es real: "...fue una foto que hice hace nueve años en Lanzarote y de la oscuridad en la que yo vivía en ese momento. De ahí viene también lo del director ciego" (Heredero-Reviriego, 2009: 10), una oscuridad que tiene que ver con la muerte -con la de su madre, acaecida en 1999- y con la aparición de los primeros síntomas de una enfermedad (unas terribles migrañas) aún no curada; la foto -fortuita, podríamos hablar de "foto encontrada"- de una playa y el descubrimiento en una esquina, casi imperceptible, de una pareja abrazada, fundida en un solo cuerpo; una foto que Mateo Blanco en la ficción también toma y que se integrará como un elemento más de su huída-refugio junto a Lena en Lanzarote, una isla (no lo olvidemos) de origen volcánico y lugar histórico de destierro, refugio y de exilio forzado.

Es decir, ya en el primer acercamiento a la ficción se parte de unas realidades vividas que la foto consagra, para después, según él mismo confiesa, comenzar el proceso de invención: la historia de esa pareja real y viva pero ausente, muerta pero existente, y en esa isla, en aquél momento: "La segunda línea me la tengo que inventar, y ese es el juego que me atrae, porque primero debo descubrirla, y no la quiero descubrir en la realidad. Prefiero descubrirla en la imaginación" (Heredero-Reviriego, 2009: 10). Hay, pues, toda una poética sobre el azar en un sentido surrealista muy ligada a la teoría (desde Benjamin a Barthes, desde Sontag a Dubois, desde Freund a Debray) sobre la fotografía como punctum indicador de la muerte, es decir como realidad congelada, de "lo 
que ha sido" y estuvo allí delante del objetivo de la cámara en aquel preciso instante; es por ello que $a b$ initio la película surge de una experiencia personal de su vida real en un momento en que el paisaje volcánico, negro, de la isla concuerda con su estado anímico igualmente oscuro y que la foto al cabo del tiempo se encarga de actualizar: "Las fotos captan cosas que el ojo no ve a primera vista. Las fotos adquieren una densidad y expresividad que multiplican con mucho la emoción y la realidad del momento en que se hizo" (Sardá, 2009: 47); es decir, partimos de la imagen fotográfica, que es detención del tiempo, oscuridad y muerte pero mágica revelación de lo invisible -imposible no recordar aquí la alusión al planteamiento de Blow-up de Antonioni- y en un estado de ceguera, por supuesto metafórica, de olvido de lo visible, que representa Harry Caine (Lluis Homar) en la trama, hay que inventar la historia de esa pareja de amantes con el solo concurso de la imaginación; lo que sucede es que el imaginario de Almodóvar está poblado casi en exclusiva de esas imágenes reminiscentes o anamnésicas procedentes de otras películas que "salen como un elemento dramático del guión, casi como un personaje del que me sirvo" (Heredero-Reviriego, 2009: 10). Para Almodóvar entonces inventar la historia en base a su imaginación, inspirada en el cine, supone siempre, pero aún más en Los abrazos rotos, pasar de la muerte a la vida, de la oscuridad a la luz, pero a una luz interior que sirve para iluminarle en el momento de encajar los diferentes elementos del puzzle fílmico en una historia propia: hacer una película en base a otras películas, hacer cine sobre cine.

Pero el travestí tiene también una pulsión voyeurística innegable que se manifiesta en la abundancia en casi todas sus películas de fotos pegadas en la pared o reproducidas en revistas, de ojos, de cerraduras, de objetivos, pues la cámara se torna ojo corporal como medio para conquistar la realidad pero también como medio para que el travestí sea visto en su otra identidad, la interior, que ahora, en el decurso temporal del film, se externaliza. No es casualidad por lo tanto que Peeping Tom (El fotógrafo del pánico, 1960) sea su película más socorrida en este sentido: desde Kika hasta Los abrazos rotos pasando por La mala educación subsiste esa obsesión por eternizar el instante fugitivo (que aquí representa Ernesto Jr., con su making-off, presencia constante del falo paterno), en matar simbólicamente al objeto amado: "El ojo del fotógrafo siempre está como redoblando las imágenes [se refiere a Kika], 
desdoblando los sentidos" (Seguin, 2009: 194), pero es una muerte que es vida puesto que subsiste en imagen, aunque sólo pueda ser percibida mediante el tacto, como en ese momento culminante en que Harry Caine toca la pantalla del televisor "recordando" en tanto que "vivido/visto" ese último beso que dio a la amada antes de morir fatalmente. Y es que si el cine es el terrritorio del doble, la fotografía propicia ese continuo desdoblarse de todos los elementos puestos en liza por el director y coadyuva a su transformación mediante el ojo travestido en cámara: de lo uno en lo otro, de lo fijo en lo móvil, de lo masculino en lo femenino, del tiempo en el espacio, etc., pero todo en su caso con su correspondiente viceversa o "tanto monta"; es ni más ni menos que el privilegio (o la tortura) de ser un "ser doble" asumiendo los problemas de identidad sexual que ello comporta.

\section{De la fotografía al molde vivo... calcinado}

Pero, para que Los abrazos rotos, sea fusión de fusiones, y sobre todo reflexión sobre el tiempo momificado, sobre la muerte, hace falta que el azar se ficcionalice doblemente, es decir, que no sea fruto de un azar real como en la foto -fijación muerta al fin y al cabo- sino que esa misma realidad se torne cine -movimiento, simulacro de vida- como consecuencia igualmente de la intervención del azar en su discurrir como doble de la vida representada. Y ahí es donde interviene el recurso a la secuencia de Viaggio in Italia (Te querré siempre, 1953) de Roberto Rossellini, respecto de la cual sabemos fue fruto del azar, pues Rossellini no tenía previsto, según cuentan las fuentes (Guarner 1972; Rossellini 2005; Quintana 1995; Hovald 1962), que en el momento de la filmación se estuviera sacando un molde de la pareja de amantes calcinados por la lava del Vesubio, por eso la elección de Almodóvar es distinta por partida doble a las citas textuales de otras películas realizadas anteriormente (como en la relación All about Eve-Todo sobre mi madre o Ensayo de un crimen-Carne trémula), ya que tiene en cuenta incluso -lo que es raro- las condiciones originales de rodaje del documento fílmico original (incluída su faceta estrictamente documental) aparte, claro está, las referencias, en este caso efectivas y profundas, al momento culminante de la trama argumental de la “película-marco" (Bowie, 2005) con la cual establece una complicidad 
manifiesta y coherente con el planteamiento del arranque fotográfico -momificación del tiempo- y que lleva a la película, en el fondo, a ser una reflexión sobre la muerte, sobre la imposibilidad del arte -en este caso la fotografía y el cine-de expresar la verdad de la vida.

Lo primero que destaca Almodóvar es su condición de película-faro, es decir, iluminadora, incluso para la "nouvelle vague", por su transparencia, por estar rodada en exteriores y con pocos artificios (Ciment-Rouyer, 2009: 11), pero, sobre todo, por su planteamiento nada apriorístico acerca de la verdad en el cine en relación con la realidad pues en ella se desarrolla la idea de que el cine "no puede partir de una verdad anterior, preescrita en el guión, sino de una verdad revelada" (Quintana, 1997: 161) y la realidad es "vista como un mundo objetivo, preexistente que actúa en la conciencia de los personajes" (ibid., 162), y el mundo exterior "existe de una forma independiente a la ficción, pero puede afectar profundamente al interior de unos personajes ficticios sumidos en una profunda crisis existencial" (ibid.).

En efecto, la secuencia escogida, cuando la pareja formada por Katherine y Alex (Ingrid Bergman y George Sanders) visita las ruinas de Pompeya, es paradigmática de esa iluminación que proyecta sobre el resto del film de Rossellini y sobre el de Almodóvar, pues en éste forma parte como un personaje más de la trama y además está colocada, no al principio como en los casos antes citados, en el quicio, en el eje argumental de su película: en el recuerdo más doloroso de Mateo Blanco, el de la felicidad que precede a la tragedia y que inmortaliza en una autofoto como si presintiera que ese momento no volvería más. En ese instante de vida, contemplando la película en un pase televisivo, Lena, al ver la turbación de Katherine-Ingrid Bergman tras ver ella a su vez los cuerpos calcinados de los amantes, se identifica con ella y siente lo mismo que ella: le gustaría morir así y ser "modelada" como esa pareja pompeyana para la eternidad, pero intuye que ese no será su caso, que tendrá que conformarse con la inmortalidad que le proporcionan las sombras en la pantalla o las imágenes grabadas por el sol en el papel fotográfico.

En torno a esta identificación Lena-Katherine y el abrazo eternizado, Almodóvar teje una sutil urdimbre de otras identificaciones que es lo que le otorga a Los abrazos rotos una especial significación dentro de la estética almodovariana y 
sus planteamientos metacinematográficos, muy alejados ya por fortuna de "esa ligereza con la que el realizador recoge restos de una tradición audiovisual cualquiera y los coloca unos junto a otros, despreocupándose a continuación de los nexos que los unen” (Sánchez Biosca, 1995: 61). Así, por ejemplo, la profunda relación metafórica que se establece entre Pompeya y Lanzarote debido a su común carácter volcánico y que tanto en un caso como en otro condicionan "geológicamente" a las parejas implicadas, puros volcanes a punto de estallar -los Joyce por su propia abulia existencial y Lena-Mateo por la persecución a que les somete Ernesto Martel. Pero junto a la geología hay también una "geografía”, unas islas a las que se viaja, so pretexto de un turismo ficticio, para huir en ambos casos y desembocar en un descubrimiento personal que consolida milagrosamente la relación o la destruye: si en un caso se viaja al pasado y ese pasado se muestra inquieta y atrozmente benéfico, en el otro se viaja fatalmente hacia el olvido que unas fotografías (más que abrazos) rotas no pueden rescatar de un tiempo que Mateo -ya Harry Caine- quiere dejar para siempre encerradas en ese cajón cuya cerradura sólo podrá ser abierta por su hijo no declarado, su lazarillo.

Es por eso que no tiene nada de extraño que, como el mismo Almodóvar reconoció, uno de los protagonistas de Los abrazos rotos sea "la propia construcción del relato" (Heredero-Reviriego, 2009: 7) pues se tiene la impresión de que esta vez sí que hay un arquitecto que ensambla mejor que antes todos los elementos heterogéneos puestos en liza y que el puzzle o la coctelera están manejados con brío y sentido del ritmo. Y ello se debe en mi opinión a que el "faro" cumple una doble función: iluminadora por un lado y falocrática por otro, pudiéndose decir respecto a lo primero que "una ficción del pasado irrumpe en el interior de una ficción del presente, a la que trata de legitimar culturalmente y a la que sirve como espejo. La ficción se mira en la ficción. El cine se mira en el cine" (Heredero, 2009: 47) y respecto a lo segundo que la parte masculina de la mirada travestida (al menos en esta película) sale triunfante debido a que por lo menos una de sus manifestaciones, los papelespersonajes masculinos (salvo algún desliz) mantienen un cierto equilibrio con los papeles-personajes femeninos, con lo que la transgresión implícita en su mirada está más amortiguada que nunca; lo que equivale a decir en su caso que Almodóvar en la medida que madura retorna al clasicismo y se reconoce entre 
sus maestros: así Rossellini no podía ser menos que Visconti, Fellini y Antonioni; al menos con él ha descubierto el milagro de que el cine no tiene nada que ver con la realidad sino que es pura y simplemente revelación del fluir de la vida, y como tal también de la muerte, a la que ya se atreve a mirar directamente a la cara y hasta coquetear con ella.

\section{Referencias bibliográficas}

ALARCON, Tonio L., (2006). "Pedro Almodóvar: cine provocación". Dirigido por..., $\mathrm{n}^{\mathrm{O}} 355$, pp. 40-59.

ALMODOVAR, Pedro. (2006). Almodovar Exhibition. Paris: Cinemathéque Française; Madrid: El Deseo, 2006. Fascículo VII. La vie spectacle.

BARTHES, Roland, (1982). La cámara lúcida. Barcelona: Gustavo Gili.

BREMARD, Benedicte, (2003). Le cinéma de Pedro Almodóvar: tissages et métissages. Paris: Difussion ANRT.

CIMENT, Michel et Philippe Rouyer, (2009) "Etreintes brisées. Mirage de la vie". Positif, no 579, pp. 9-13

D’LUGO, Marvin, (2005). “Genealogía de las "sórdidas comedias Neosurrealistas almodovarianas”. En: Zurian, Fran y Carmen Vázquez Varela, (eds.). Almodóvar: el cine como pasión. Cuenca: Ediciones de la Universidad de Castilla-La Mancha, pp. 81-91.

FERNANDEZ-SANTOS, Elsa, (2009). “Historia de un abrazo”. El Pais Semanal, 8 marzo, pp. 54-58.

GENETTE, Gérard, (1989). Palimpsestos. La literatura en segundo grado. Madrid: Taurus.

GRENIER, Pascal, (2010). "Etreintes brisées. Je me fais mon cinema". Séquences, $\mathrm{n}^{\mathrm{O}}$ 264, janvier-février, pp. 42-43.

GUARNER, José Luis (1972). Roberto Rossellini. Madrid: Fundamentos.

HEREDERO, Carlos F. y Carlos Reviriego, (2009) "Entrevista Pedro Almodóvar. El cine protector". Cahiers du Cinéma España, no 21, pp. 6-13.

HERRERA, Javier, (2012). "El cine dentro del cine en la obra de Pedro Almodóvar: pasión cinéfila y tradición barroca”. En: MATZ, Maria and Carole Salmon (ed.), How the Films of Pedro Almodovar Draw Upon and Influence Spanish Society: Bilingual Essays on His Cinema. New York: Mellen Press, pp. 67-85.

HOVALD, Patrice, (1962). El neorrealismo y sus creadores. Madrid: Rialp.

J.-L.L., (2009). Almodovar et la cinéphile: du décalquage au palimpseste. http://www.cineclubdecaen.com/realisat/almodovar/. Consultado 10.2.2011

KINDER, Marsha, (2010). "Restoring Broken Embraces. On cinema's resilience, intertextuality, and father-son relations in "Almodovar 8". Film Quaterly, vol. $63, \mathrm{n}^{\mathrm{o}} 3$, pp. 28-34.

LAW, Clementine, (2010). La intertextualidad en el cine de Pedro Almodóvar. [Trabajo de Licenciatura] Clermont-Ferrand: Université Blaise Pascal. 
MAURER QUEIPO, Isabel, (2008). "La estética de lo híbrido en Hable con ella de Pedro Almodóvar”. En: FEENSTRA, Pietsie y Hub. Hermans (eds), Miradas sobre pasado y presente en el cine español (1990-2005). Amsterdam-New York: Rodopi.

METZ, Christian, (1998). Filme(s) en el film. El intexto fímico. Valencia: Ediciones Episteme.

PEREZ BOWIE, José Antonio, (2005). "El cine en, desde y sobre el cine: metaficción, reflexividad e intertextualidad en la pantalla". Anthropos, $\mathrm{n}^{\mathrm{o}}$ 208, pp. 122-137.

POYATO, Pedro, (2007). Todo sobre mi madre. Valencia: Nau Llibres; Barcelona: Octaedro.

SARDÁ, Juan, (2009). [El regreso de Almodóvar. Entrevista]. El Cultural, 13 marzo, pp. 44-47.

QUINTANA, Angel, (1995). Roberto Rossellini. Madrid: Cátedra.

QUINTANA, Angel, (1997). El cine italiano, 1942-1961. Del neorrealismo a la modernidad. Barcelona: Paidós.

ROSSELLINI, Roberto (2005). Roberto Rossellini. La herencia de un maestro. Valencia: IVAC. La Filmoteca; Barcelona: Filmoteca de Catalunya; Madrid: Filmoteca Española.

SANCHEZ-BIOSCA, Vicente, (1995). Una cultura de la fragmentación: pastiche, relato y cuerpo en el cine y la televisión. Valencia: Filmoteca Generalitat Valenciana.

SEGUIN, Jean-Claude, (2009). Pedro Almodóvar o la deriva de los cuerpos. Murcia: Tres Fronteras Ediciones.

STRAUSS, Frederic, (1999). “A coeur ouvert. Entretien avec Pedro Almodovar”. Cahiers du Cinéma, no 535, pp. 36-40.

YARZA, Alejandro (1999). "Estudios cinematográficos. «La herida al aire : travestismo y ansiedad cultural en el cine de Pedro Almodóvar”. En: DEL PINO, José María, Francisco La Rubia Prado (eds.), El hispanismo en los Estados Unidos. Discursos críticos-Prácticas textuales. Madrid: Visor. 